\title{
Sleep Deprivation Selectively Impairs Memory Consolidation for Contextual Fear Conditioning
}

\author{
Laurel A. Graves, ${ }^{1}$ Elizabeth A. Heller, ${ }^{2,5}$ Allan I. Pack, ${ }^{3}$ and Ted Abel ${ }^{1,4,6}$ \\ ${ }^{1}$ Neuroscience Graduate Group, University of Pennsylvania School of Medicine, Philadelphia, Pennsylvania 19104, USA; ${ }^{2}$ College of Arts and \\ Sciences, University of Pennsylvania, Philadelphia, Pennsylvania 19104, USA; ${ }^{3}$ Center for Sleep and Respiratory Neurobiology, University of \\ Pennsylvania School of Medicine, Philadelphia, Pennsylvania 19104, USA; ${ }^{2}$ Department of Biology, University of Pennsylvania, \\ Philadelphia, Pennsylvania 19104, USA
}

\begin{abstract}
Many behavioral and electrophysiological studies in animals and humans have suggested that sleep and circadian rhythms influence memory consolidation. In rodents, hippocampus-dependent memory may be particularly sensitive to sleep deprivation after training, as spatial memory in the Morris water maze is impaired by rapid eye movement sleep deprivation following training. Spatial learning in the Morris water maze, however, requires multiple training trials and performance, as measured by time to reach the hidden platform is influenced by not only spatial learning but also procedural learning. To determine if sleep is important for the consolidation of a single-trial, hippocampus-dependent task, we sleep deprived animals for 0-5 and 5-10 $\mathrm{h}$ after training for contextual and cued fear conditioning. We found that sleep deprivation from $0-5 \mathrm{~h}$ after training for this task impaired memory consolidation for contextual fear conditioning whereas sleep deprivation from 5-10 h after training had no effect. Sleep deprivation at either time point had no effect on cued fear conditioning, a hippocampus-independent task. Previous studies have determined that memory consolidation for fear conditioning is impaired when protein kinase A and protein synthesis inhibitors are administered at the same time as when sleep deprivation is effective, suggesting that sleep deprivation may act by modifying these molecular mechanisms of memory storage.
\end{abstract}

Sleep has been proposed to serve a variety of physiological purposes, ranging from thermoregulation to the maintenance of immune function (Rechtschaffen 1998). One important hypothesis is that sleep is a regulator of neuronal function during memory storage (for review, see Graves et al. 2001; Stickgold et al. 2001). Sleep after training appears to influence memory consolidation for a variety of tasks in humans and experimental animals (e.g., Smith 1996; Smith and Rose 1996; Stickgold et al. 1999, 2000). To understand the nature of the influence of sleep on memory consolidation, it is important to understand which neural systems are involved. Given our knowledge of the molecular mechanisms of memory consolidation (Abel and Lattal 2001), this systems approach may also provide a means to define the molecular mechanisms underlying the role of sleep in memory consolidation.

To study the neural systems involved in the effects of sleep deprivation, researchers have focused on tasks such as the Morris water maze (Morris et al. 1982). Spatial learning in the Morris water maze, which can be configured to be hippocampus dependent, is a multi-trial task over multiple

${ }^{5}$ Present address: Rockefeller University, New York, NY 10021, USA.

${ }^{6}$ Corresponding author.

E-MAIL abele@sas.upenn.edu; FAX (215) 898-8780.

Article and publication are at http://www.learnmem.org/cgi/doi/ $10.1101 / \mathrm{lm} .48803$. days in which animals learn to find a submerged, hidden platform in a pool of water by using spatial cues (Morris et al. 1982). In rats, rapid eye movement (REM) sleep deprivation during specific time periods after training for the hidden-platform version of the Morris water maze disrupts memory consolidation, as measured by an increase in time to reach the hidden platform (Smith and Rose 1996; Smith and Rose 1997). Performance in the visible-platform version of the water maze, which is hippocampus-independent, is not affected by REM sleep deprivation (Smith and Rose 1996, 1997). In a separate set of experiments, it was shown that REM sleep in rats is increased after training for the hidden-platform version, but not the visible-platform version, of the water maze (Smith and Rose 1997). These experiments examining spatial memory have provided important support for the idea that sleep plays a central role in the regulation of neuronal function within the hippocampus. However, it is possible for animals to use a procedural, nonhippocampus-dependent strategy to learn the location of the hidden platform (Schenk and Morris 1985; Lipp and Wolfer 1998).

The single-trial task of fear conditioning provides a behavioral paradigm with which to study the effects of sleep selectively on memory consolidation and to compare this with what is known about the molecular mechanisms of memory consolidation. Fear conditioning is a single-trial associative learning task in which an animal learns to fear a new environment (context) or a discrete conditioned stimu-

LEARNING \& MEMORY 10:168-176 @ 2003 by Cold Spring Harbor Laboratory Press ISSN1072-0502/03 \$5.00

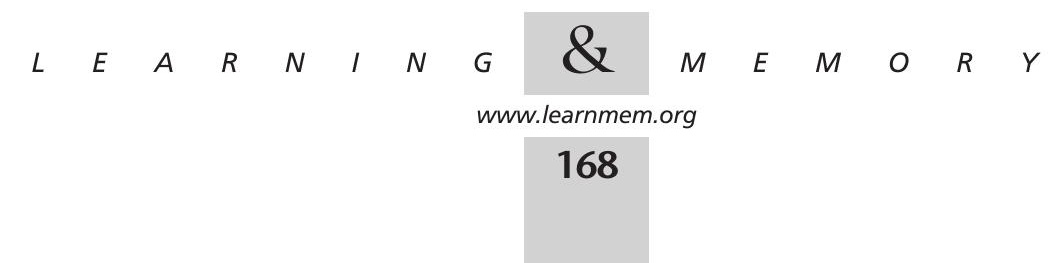


lus (CS) or cue, such as white noise, because of the association between these conditioned stimuli and an aversive unconditioned stimulus (US), footshock (for review, see LeDoux 2000; Maren 2001). When exposed to the same context or cue some time after training, animals exhibit a variety of fear responses, including freezing behavior (Blanchard and Blanchard 1969; Fanselow 1980). Whereas both contextual and cued learning are amygdala dependent, contextual learning is also hippocampus dependent (for review, see Holland and Bouton 1999). The use of fear conditioning to investigate the role of sleep in memory consolidation has several advantages. It is clear that there are discrete stages of memory including learning, consolidation, retrieval, and reconsolidation (for review, see Abel and Lattal 2001). Because fear conditioning is a task that induces robust learning and memory following a single trial, the task of fear conditioning may enable a more thorough analysis of the precise time course of molecular changes associated with long-term memory consolidation and the influence of sleep on those changes. Further, fear conditioning allows us to examine the effects of sleep deprivation on hippocampal and amygdala function.

It is now clear that memory consolidation happens over a period of hours to days after training for a task (Abel and Lattal 2001), and that activity of cellular signaling pathways at precise times after training is necessary for consolidation (e.g., Izquierdo and Medina 1997; Bourtchouladze et al. 1998). For instance, disruption of protein kinase A (PKA) signaling and protein synthesis at $0 \mathrm{~h}$ and $4 \mathrm{~h}$, but not $6 \mathrm{~h}$, after training for fear conditioning disrupts long-term memory for this task (Bourtchouladze et al. 1998). By defining a time window in which sleep affects fear conditioning, we may be better able to understand the relationship between cellular and molecular processes that affect fear conditioning at those times and the influence of sleep on those processes. Here, we report that sleep deprivation from $0-5 \mathrm{~h}$, but not 5-10 h, after training impairs the consolidation of memory for contextual fear conditioning when mice are tested $24 \mathrm{~h}$ after training. We saw no effects of sleep deprivation from $0-5 \mathrm{~h}$ or from $5-10 \mathrm{~h}$ on cued conditioning. These results lead us to conclude that sleep deprivation affects hippocampus-dependent memory consolidation, including spatial and contextual aspects of hippocampal function. Portions of this work have appeared previously in abstract form (Graves et al. 1999).

\section{RESULTS}

To determine if there is a window of time that is sensitive to sleep deprivation after training for fear conditioning, we performed sleep deprivation at two different time periods after training for this task. We chose the time periods of 0-5 $\mathrm{h}$ and 5-10 $\mathrm{h}$ after training to roughly coincide with times that have shown to be sensitive or insensitive to PKA and protein synthesis inhibition (Bourtchouladze et al. 1998).
To examine both contextual and cued fear conditioning, mice were trained in the presence of a discrete auditory cue, with the training time held constant.

\section{Sleep Deprivation From 0-5 H After Training Impairs Memory Consolidation for Contextual Conditioning but Not Cued Conditioning}

Mice sleep deprived from $0-5 \mathrm{~h}$ after training showed reduced freezing in the shocked context when tested $24 \mathrm{~h}$ after training (Fig. 1A; context; $25.2+/-3.2 \%$ and $15.7+/-$ $3.2 \%$ for nonsleep-deprived and sleep-deprived mice, respectively). Sleep-deprived mice did not significantly differ from nonsleep-deprived mice in levels of freezing in the altered context (Fig. 1A; pre CS; $8.6+/-2.7 \%$ and $16.1+/-$ $3.1 \%$ for nonsleep-deprived and sleep-deprived mice, respectively). There was no difference between sleep-deprived and nonsleep-deprived mice in levels of freezing in
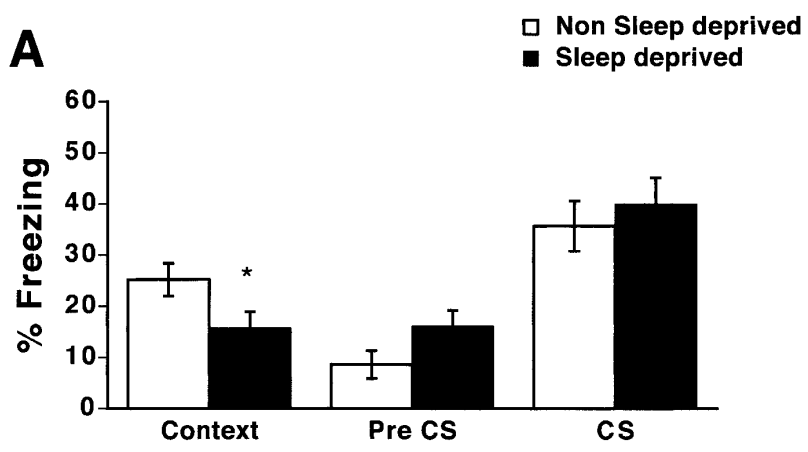

B

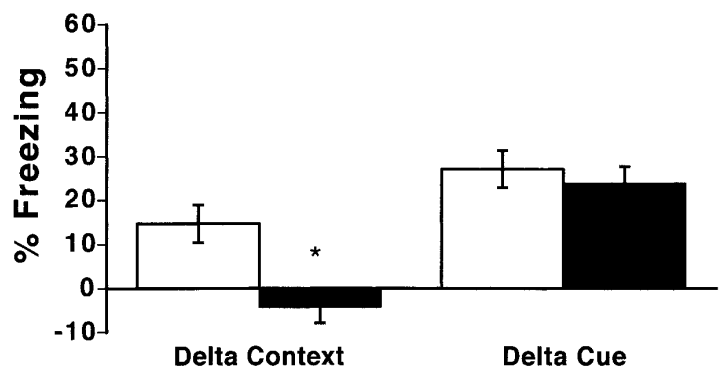

Figure 1 Total sleep deprivation from $0-5 \mathrm{~h}$ after training selectively impairs memory for contextual conditioning. (A) Mice sleep deprived from $0-5 \mathrm{~h}$ after training freeze less in response to the shocked context than do nonsleep-deprived mice (context; $P<.05$; $\mathrm{n}=21$ per group). Sleep-deprived mice did not differ from nonsleep-deprived mice in freezing in the altered chamber (preconditioned stimulus [pre CS]) or in freezing in response to the noise cue (conditioned stimulus [CS]; $P>.05 ; \mathrm{n}=15$ per group). (B) Mice show a deficit in the specificity of freezing to the shocked context when sleep deprived from $0-5 \mathrm{~h}$ after training for fear conditioning. Specificity of freezing to the shocked context (delta context) measured by the difference in percent freezing between the shocked and altered context was significantly less in mice that were sleep deprived from $0-5 \mathrm{~h}$ after training than in nonsleep-deprived mice $(P<0.01 ; \mathrm{n}=15$ per group). Cue-specific freezing (delta cue) is not altered by sleep deprivation from $0-5 \mathrm{~h}$ after training $(P>.05$; $\mathrm{n}=15$ per group). ${ }^{*}, P<.05$.

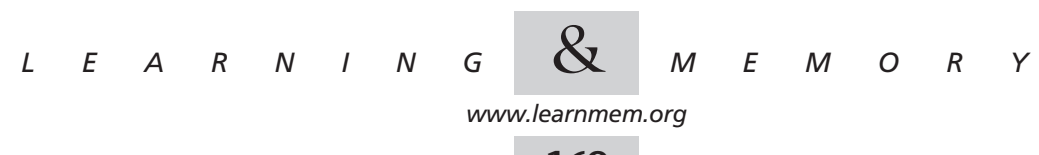


response to the noise cue (Fig. $1 \mathrm{~A} ; \mathrm{CS} ; 35.7+/-4.9 \%$ and $40.0+/-5.1 \%$ for nonsleep-deprived and sleep-deprived mice, respectively).

To control for any nonspecific effects of sleep deprivation on fear conditioning, we also calculated the difference in freezing levels between the shocked context and the altered, nonshocked context for each mouse (delta context score; Paylor et al. 1994). Context-specific freezing was significantly higher for nonsleep-deprived mice (Fig. 1B; delta context; $14.7+/-4.3 \%$ and $-4.3+/-3.6 \%$ for nonsleep-deprived and sleep-deprived mice, respectively). This demonstrated that a specific association between the shocked context and the footshock had not been achieved for sleep-deprived mice (Paylor et al. 1994; Frankland et al. 1998). In contrast, there was no effect of sleep deprivation on cue-specific freezing (Fig. 1B; delta cue score; 27.1 +/$4.2 \%$ and $23.9+/-3.8 \%$ for nonsleep-deprived and sleepdeprived mice, respectively).

A two-way ANOVA of the tests of context, pre CS, and CS revealed that there was a reliable main effect of the condition of testing $(\mathrm{F}[2,101]=21.72, P<.001)$, that there was not an overall reliable effect of sleep deprivation ( $\mathrm{F}[1$, 101] $=0.057, P>.05)$, but that the interaction between sleep deprivation and the condition of testing was reliable $(\mathrm{F}[2,101]=3.18, P<.05)$. A two-way ANOVA of the delta context and delta cue scores revealed that there was a reliable main effect of the condition of testing ( $\mathrm{F}[1$, $59]=26.37, P<.001)$, that there was an overall reliable effect of sleep deprivation $(\mathrm{F}[1,59]=7.93, P<.05)$, and that the interaction between sleep deprivation and the condition of testing approached significance $(F[1,59]=4.00$, $P=.05)$. Overall, post-hoc tests revealed that sleep deprivation significantly impaired contextual fear conditioning and the delta context score $(P$ 's $<.05)$ without significantly altering pre-CS- or CS-evoked freezing, or the delta cue score (P's > .05).

To ensure that levels of freezing in response to the cue were specific for an association between the cue and the footshock and were not from generalized fear, a group of nonsleep-deprived mice that had received no noise-shock pairing during training were tested $24 \mathrm{~h}$ following training for freezing in response to the noise cue. These animals showed $13.2+/-3.2 \%(n=12)$ freezing in response to the cue, indicating that the levels of freezing seen $24 \mathrm{~h}$ following a noise-shock pairing in nonsleep-deprived mice (Fig. 1; CS; $35.7+/-4.9 \%$ ) were specific for an association between the cue and the footshock $(P<.05)$. Analysis of sleepdeprived mice revealed a similar amount of freezing (13.9 $+/-3.7 \% ; \mathrm{n}=12$ ) to a nonconditioned cue.

To determine if testing order altered the effects of sleep deprivation on freezing, we reversed the order of testing in an additional group of trained mice, measuring cued fear conditioning first and then contextual fear. Sleep deprivation ( $0-5 \mathrm{~h}$ following training) still selectively im- paired contextual fear conditioning even when the context test followed the cued test (Fig. 2A; context; $30.0+/-5.7 \%$ and $13.9+/-3.9 \%$ for nonsleep-deprived and sleepdeprived mice, respectively). There was no difference between sleep-deprived and nonsleep-deprived mice in levels of freezing in response to the cue (Fig. 2A; CS; $46.6+/-$ $5.0 \%$ and $47.2+/-6.6 \%$ for nonsleep-deprived and sleepdeprived mice, respectively).

To control for any interaction of sleep deprivation with the order of testing, we also calculated a delta context and a delta cue score. Context-specific freezing was significantly higher for nonsleep-deprived mice (Fig. 2B; delta context; $16.1+/-7.1 \%$ and $-8.3+/-5.7 \%$ for nonsleep-deprived and sleep-deprived mice, respectively). In contrast, there was no effect of sleep deprivation on the delta cue score (Fig.
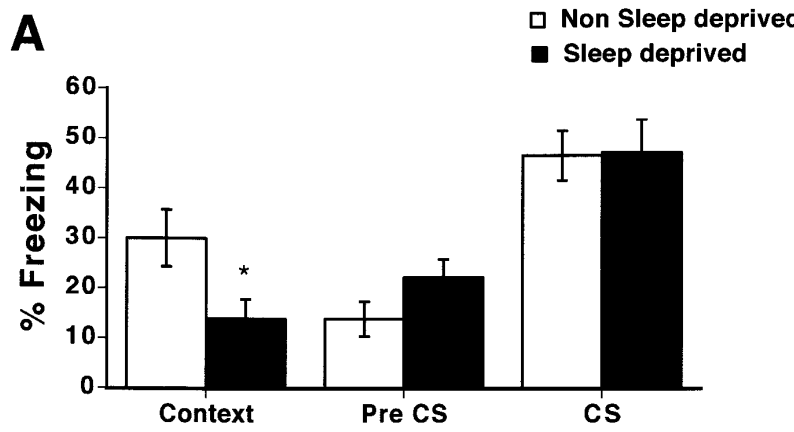

B

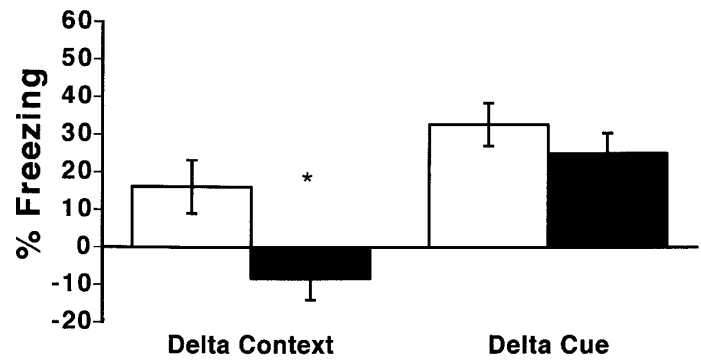

Figure 2 Order of testing does not affect impairments in memory for contextual conditioning as a result of $0-5 \mathrm{~h}$ of total sleep deprivation after training. Mice were trained similarly to the experiment shown in Figure 1, however, freezing in response to the conditioned stimulus (CS) in an altered context was tested at $24 \mathrm{~h}$ following training before freezing in response to the shocked context was tested. (A) Mice sleep deprived from $0-5 \mathrm{~h}$ after training freeze less in response to the shocked context than do nonsleepdeprived mice (context; $P<.05 ; \mathrm{n}=9$ per group). Sleep-deprived mice did not significantly differ from nonsleep-deprived mice in freezing in the altered chamber (pre CS) or in freezing in response to the cue (CS; $P^{\prime} \mathrm{s}>.05 ; \mathrm{n}=9$ per group). (B) Mice show a deficit in the specificity of freezing to the shocked context when sleep deprived from $0-5 \mathrm{~h}$ after training. Specificity of freezing to the shocked context (delta context) measured by the difference in percent freezing between the shocked and altered context was significantly less in mice that were sleep deprived from $0-5 \mathrm{~h}$ after training than in nonsleep-deprived mice $(P<.01 ; \mathrm{n}=9$ per group). Cue-specific freezing (delta cue) is not altered by sleep deprivation from $0-5 \mathrm{~h}$ after training $\left(P>.05 ; \mathrm{n}=15\right.$ per group). ${ }^{*}, P<.05$.

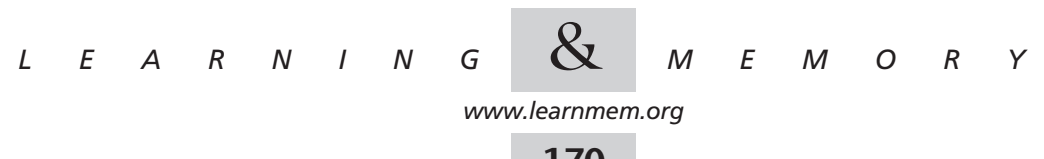


2B; delta cue; $32.7+/-5.7 \%$ and $25+/-5.4 \%$ for nonsleepdeprived and sleep-deprived mice, respectively).

A two-way ANOVA of the tests of context, pre CS, and CS with the cue test performed first revealed that there was a reliable main effect of the condition of testing ( $\mathrm{F}[2$, 53 ] $=20.47, P<.01$ ), that there was not an overall reliable effect of sleep deprivation $(\mathrm{F}[1,53]=0.36, P>.05)$, and that the interaction between sleep deprivation and the condition of testing was reliable $(\mathrm{F}[2,53]=3.26, P<.05)$. A two-way ANOVA of the delta context and delta cue scores with the cue test performed first revealed that there was a reliable main effect of the condition of testing ( $\mathrm{F}[1$, $35]=17.30, P<.001)$, that there was an overall reliable effect of sleep deprivation $(\mathrm{F}[1,35]=7.16, P<0.05)$, but that the interaction between sleep deprivation and the condition of testing was not reliable $(\mathrm{F}[1,35]=1.95, P>.05)$. Overall, post-hoc tests revealed that sleep deprivation significantly impaired contextual fear conditioning and the delta context score $(P$ 's $<.05)$ without significantly altering pre-CS- or CS-evoked freezing or the delta cue score ( $P$ 's $>0.05)$.

To determine if there is an interaction between freezing in response to the cue and the strength of cued conditioning, we trained a group of animals with a tone CS instead of the noise CS while keeping all other aspects of the experiment constant. This resulted in lower levels of freezing in response to the tone in nonsleep-deprived mice (Fig. 3A) when compared to levels of freezing in response to the noise in nonsleep-deprived mice (Fig. 1A). Mice sleep deprived from $0-5 \mathrm{~h}$ after training did not exhibit significant reductions in levels of freezing in response to the tone (Fig. $3 \mathrm{~A} ; 14.4+/-2.2 \%$ and $21.3+/-4.1 \%$ in nonsleep-deprived and sleep-deprived mice, respectively) or in levels of cuespecific freezing (Fig. 3B; delta cue, $6.4+/-3.5 \%$ and 10.5 $+/-2.7 \%$ in nonsleep-deprived and sleep-deprived mice, respectively). Sleep-deprived mice showed reduced freezing in the shocked context when tested $24 \mathrm{~h}$ after training (Fig. 3A; context; $24.4+/-3.3 \%$ and $16.1+/-2.8 \%$ for nonsleep-deprived and sleep-deprived mice, respectively). There was an effect of sleep deprivation on context-specific freezing showing that sleep deprivation after training with this protocol impaired context-specific conditioning (Fig. 3B; delta context; $16.5+/-4.7 \%$ and $5.3+/-2.5 \%$ for nonsleep-deprived and sleep-deprived mice, respectively). Thus, even at lower levels of freezing, cued fear conditioning is not impaired by sleep deprivation.

A two-way ANOVA of the tests of context, pre CS, and CS revealed that there was a reliable main effect of the condition of testing $(\mathrm{F}[2,71]=6.07, P<.01)$, but that there was not an overall reliable effect of sleep deprivation (F[1, $71]=0.03, P>.05)$. The interaction between sleep deprivation and the condition of testing approached statistical significance $(\mathrm{F}[2,71]=2.90, P=0.06)$. A two-way ANOVA of the delta cue and delta context scores revealed that there
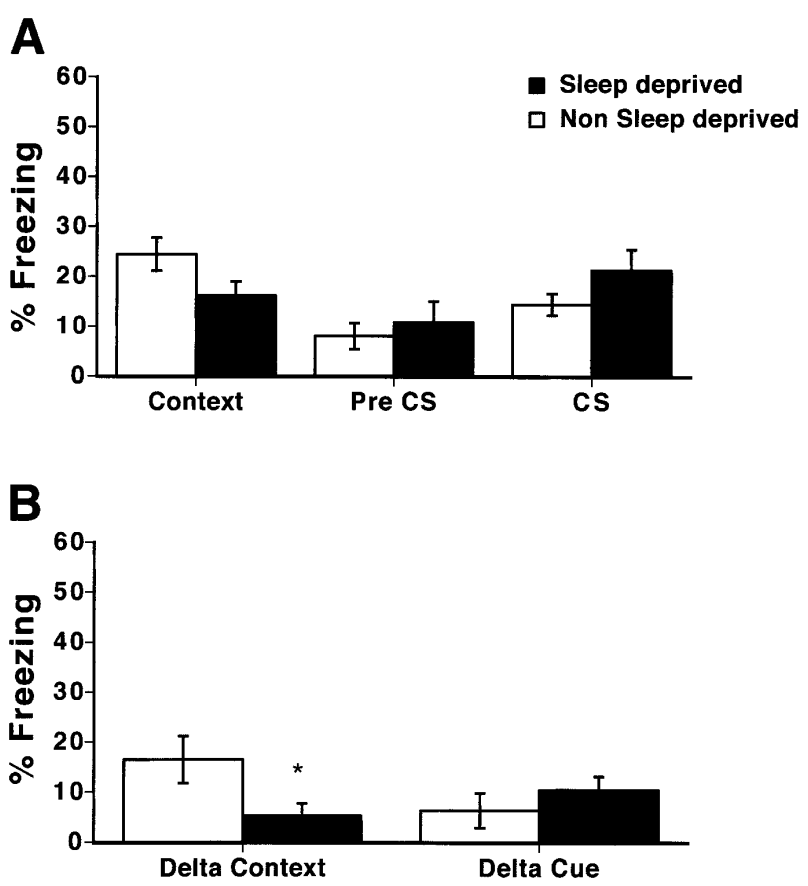

Figure 3 Total sleep deprivation from $0-5 \mathrm{~h}$ after training with a tone impairs context-specific freezing but does not impair freezing in response to the tone. Mice were trained and tested with a tone conditioned stimulus (CS), which produced lower levels of cueevoked freezing when tested $24 \mathrm{~h}$ following training than did a noise cue (Fig. 1). (A) Mice sleep deprived from $0-5 \mathrm{~h}$ after training freeze less in response to the shocked context than do nonsleepdeprived mice, although this result did not reach statistical significance (context; $P=0.077 ; \mathrm{n}=12$ per group). Sleep-deprived mice did not differ significantly from nonsleep-deprived mice in freezing in the altered chamber (pre CS) or in freezing in response to the cue (CS; $P^{\prime} \mathrm{S}>.05 ; \mathrm{n}=12$ per group). (B) Mice show a deficit in the specificity of freezing to the shocked context when sleep deprived from $0-5 \mathrm{~h}$ after training with a tone. Specificity of freezing to the shocked context (delta context) measured by the difference in percent freezing between the shocked and altered context was significantly less in mice that were sleep deprived from $0-5 \mathrm{~h}$ after training than in nonsleep-deprived mice $(P<.05 ; \mathrm{n}=12$ per group). Cue-specific freezing (delta cue) is not significantly altered by sleep deprivation from $0-5 \mathrm{~h}$ after training $\left(P>.05 ; \mathrm{n}=12\right.$ per group). ${ }^{*}$, $P<.05$.

was not a reliable main effect of the condition of testing $(\mathrm{F}[1,47]=0.50, P>.05)$, and that there was not an overall reliable effect of sleep deprivation $(\mathrm{F}[1,47]=1.00$, $P>.05)$. The interaction between sleep deprivation and the condition of testing was reliable $(\mathrm{F}[1,47]=4.85, P<.05)$. Overall, post-hoc tests revealed that sleep deprivation selectively impaired context-specific freezing as measured by the delta context score $(P<.05)$ without impairing pre-CS or CS-evoked freezing or the delta cue score ( $P$ 's $>.05)$. The effects of sleep deprivation on context-evoked fear approached statistical significance $(P=0.077)$ in this experiment. Thus, there was no effect of sleep deprivation on cue-evoked freezing at either high levels of cue-evoked freezing (with noise as the CS) or low levels of cue-evoked

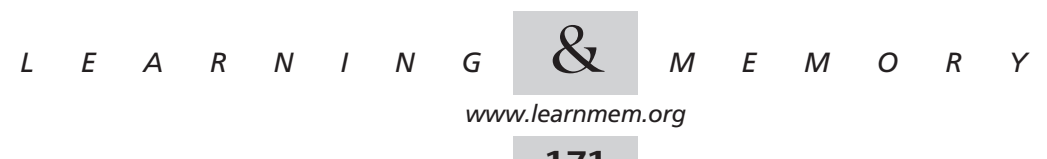


freezing (with tone as the CS), although there remained an effect of sleep deprivation on context-specific freezing (delta context)

\section{Sleep Deprivation From 5-10 h After Training Does Not Impair Memory Consolidation for Contextual Conditioning or Cued Conditioning}

To determine if there is a time window of sensitivity to sleep deprivation following training, we sleep deprived mice for 5-10 h after training. Mice sleep deprived from 5-10 h after training did not significantly differ from nonsleep-deprived mice in levels of freezing in the shocked context (Fig. 4A; context; $13.1+/-1.8 \%$ and $19.8+/-3.3 \%$ for nonsleep-deprived and sleep-deprived mice, respectively). Sleep-deprived mice did not differ from nonsleepdeprived mice in levels of freezing in the altered context (Fig. 4A; pre CS; $0.4+/-0.3 \%$ and $2.6+/-1.1 \%$ for nonsleep-deprived and sleep-deprived mice, respectively). Further, there was no difference between sleep-deprived and

A

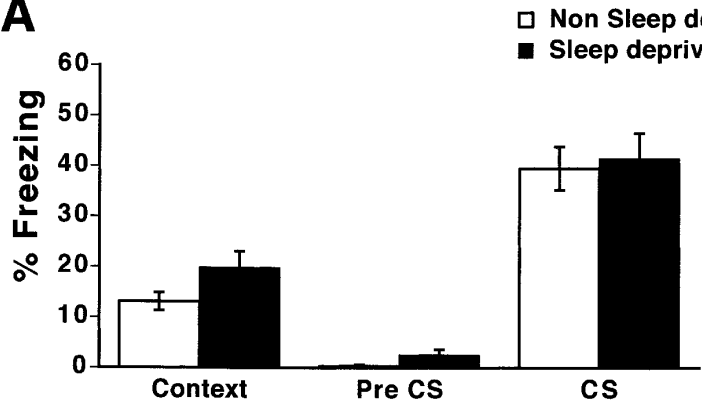

B

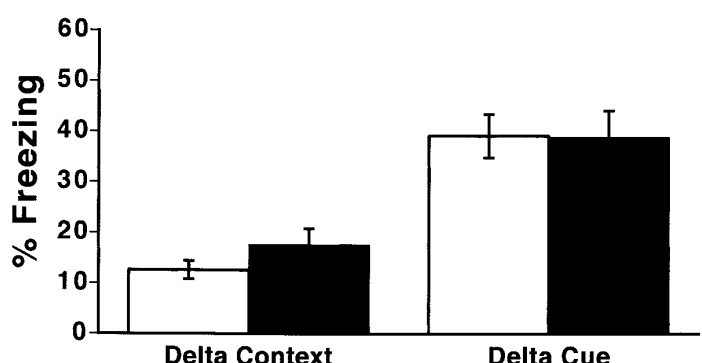

Figure 4 Total sleep deprivation from 5-10 h after training does not impair contextual or cued fear conditioning. (A) Sleep-deprived mice $(n=20)$ were not significantly different in levels of freezing in response to the shocked context than nonsleep-deprived mice ( $n=19$ per group; $P>$.05). Sleep-deprived mice did not differ from nonsleep-deprived mice in freezing in the altered chamber (pre CS) or in freezing in response to the cue $(\mathrm{n}=19$ per group; $P>.05)$. $(B)$ Specificity of freezing to the shocked context (delta context) measured by the difference in percent freezing between the shocked and altered context was not different in mice that were sleepdeprived from 5-10 $\mathrm{h}$ after training than in nonsleep-deprived mice ( $n=19$ per group; $P>.05)$. Cue-specific freezing (delta cue) is not altered by sleep deprivation from $5-10 \mathrm{~h}$ after training $(\mathrm{n}=19$ per group; $P>$.05). nonsleep-deprived mice in levels of freezing in response to the cue (Fig. 4A; cue; $39.6+/-4.3 \%$ and $41.5+/-5.1 \%$ for nonsleep-deprived and sleep-deprived mice, respectively).

In contrast to mice that were sleep deprived from $0-5$ $\mathrm{h}$ after training, mice that were sleep deprived from 5-10 h after training did not show a reduction in the specificity of freezing to the shocked context. There were no differences in the delta context freezing score (Fig. $4 \mathrm{~B}$; delta context; $12.6+/-1.8 \%$ and $17.6+/-3.2 \%$ for nonsleep-deprived and sleep-deprived mice, respectively). Similar to the $0-5 \mathrm{~h}$ group, mice that were sleep deprived from 5-10 h after training were not different from nonsleep-deprived mice in cue-specific freezing (Fig. 4B; delta cue; $39.2+/-4.3 \%$ and $38.9+/-5.3 \%$ for nonsleep-deprived and sleep-deprived mice, respectively).

A two-way ANOVA of the tests of context, pre CS, and CS revealed that there was a reliable main effect of the condition of testing $(\mathrm{F}[2,114]=76.10, P<.001)$, that there was not an overall reliable effect of sleep deprivation $(\mathrm{F}[1,114]=1.91, P>.05)$, and that the interaction between sleep deprivation and the condition of testing was not reliable $(\mathrm{F}[2,114]=0.36, P>.05)$. A two-way ANOVA of the delta cue and delta context scores revealed that there was a reliable main effect of the condition of testing ( $\mathrm{F}[1$, $75]=37.35, P<.001)$, that there was not an overall reliable effect of sleep deprivation $(\mathrm{F}[1,75]=0.36, P>.05)$, and that the interaction between sleep deprivation and the condition of testing was not reliable $(\mathrm{F}[1,75]=0.46, P>.05)$. Overall, there were no reliable effects of sleep deprivation from 5-10 h after training on either contextual or cued fear conditioning, a finding further supported by post-hoc tests that revealed that sleep deprivation from 5-10 $\mathrm{h}$ did not impair tests of context, pre CS, CS, delta context, or delta cue freezing $(P$ 's $>.05)$.

To control for effects of training at different circadian times of day, our experiments held time of training constant. This protocol was chosen because of its similarity to the behavioral procedures used in the pharmacological studies of Bourtchouladze et al. (1998). However, because groups of mice were trained at the same circadian time, mice that were sleep-deprived from 5-10 h had to be sleep deprived at a later circadian time. Because levels of sleep vary according to the time of day (Veasey et al. 2000), rodents that are sleep deprived at a later time of day may not be undergoing the same degree of sleep deprivation. For instance, animals that undergo sleep deprivation from Zeitgeber time (ZT) 5-10, during the light period, will lose more sleep than animals that undergo sleep deprivation from ZT 10-15, during $2 \mathrm{~h}$ of the light period and $3 \mathrm{~h}$ of the dark period. Because of this we also trained a 5-10-h group of mice at an earlier circadian time, ZT 0, for comparison with a group that was trained at ZT 5 . Both groups then underwent sleep deprivation from ZT 5-10; hence, the first group underwent sleep deprivation from $0-5 \mathrm{~h}$ after train-

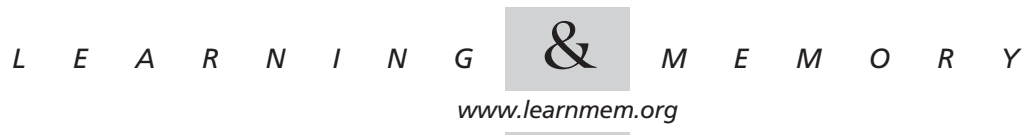


ing and the second group underwent sleep deprivation from 5-10 h after training, but in both groups sleep deprivation took place during the time period ZT 5-10. Sleep deprivation from $0-5 \mathrm{~h}$, but not from $5-10 \mathrm{~h}$ after training with this protocol also impaired specificity of freezing to the shocked context (Graves et al. 1999; L.A. Graves, E.A. Heller, and T. Abel, unpubl.).

Overall, these results indicate that sleep deprivation from $0-5 \mathrm{~h}$ after sleep deprivation impairs the specificity of freezing in response to a shocked context, whereas sleep deprivation from 5-10 $\mathrm{h}$ after sleep deprivation does not affect the context specificity of freezing. Sleep deprivation during either time point does not affect cued conditioning. These results indicate that sleep deprivation after training selectively affected hippocampus-dependent contextual learning.

\section{DISCUSSION}

Experiments in animals and humans have found that sleep deprivation after training for a variety of tasks impairs the consolidation of memory (Smith 1996; Smith and Rose, 1996; Stickgold et al. 1999, 2000; Graves et al. 2001). We have focused on the single-trial task of fear conditioning because it allows an examination of the effects of sleep deprivation on discrete neural systems with a defined time course of learning and memory (LeDoux 2000; Abel and Lattal 2001; Maren 2001). We have shown that the period of time from $0-5 \mathrm{~h}$ after training, but not from $5-10 \mathrm{~h}$ after training, is sensitive to sleep deprivation. We have also shown that contextual conditioning is sensitive to sleep deprivation, whereas cued conditioning is not. These effects were not dependent on the order of testing of contextual and cued conditioning, nor were they dependent on the strength of the cued conditioning.

In addition to measuring levels of freezing in a shocked context and a nonshocked context, we also determined the difference between freezing levels in response to a shocked and an altered, nonshocked context. This analysis enables us to examine the contextual specificity of the conditioning, which may be a very sensitive measure of hippocampal dysfunction (Frankland et al. 1998). These results support our conclusion that sleep deprivation selectively affects hippocampus-dependent memory. One additional advantage of this analysis is that it allows us to further control for nonspecific effects of sleep deprivation. Although sleep-deprived mice do not freeze significantly more in the altered context, they do show a trend toward increased freezing. Therefore, an analysis that allows us to account for changes in freezing levels that are not related to associative memory for the shocked context is useful. A similar analysis was carried out to dissociate cue-specific freezing from contextual freezing. This analysis revealed no effect of sleep deprivation on cued fear conditioning. We also examined whether or not sleep deprivation increased the levels of generalized fear. This analysis revealed low levels of freezing in response to a nontrained noise $\mathrm{CS}$ in both sleepdeprived and nonsleep-deprived animals and revealed that freezing in response to a cue was associative even in sleepdeprived mice.

Experiments have shown that circadian manipulations, such as altering the time of training and testing, may influence hippocampus-dependent memory (Rudy and Pugh 1998; Devan et al. 2001; Valentinuzzi et al. 2001). For instance, animals that are trained during their active phase have better memory for contextual, but not cued, fear conditioning compared to animals that are trained during their inactive phase (Valentinuzzi et al. 2001). Further, animals that are phase-shifted during training for the hiddenplatform version of the Morris water maze do not perform as well as controls in this task (Devan et al. 2001). It has been suggested that part of this effect may be because of the disruption of normally occurring sleep patterns, but interpreting these circadian experiments is difficult because of potential effects of the circadian manipulation on acquisition, consolidation, and retrieval. Our observations that the disruption of sleep after fear conditioning impairs contextual, but not cued, fear conditioning support the conclusion that the disruption of sleep patterns contribute to the selective impairment of hippocampus-dependent memory consolidation. Further, our use of posttraining sleep deprivation enables us to selectively alter memory consolidation.

Although we chose a method of sleep deprivation, gentle handling, that minimizes stress (Ledoux et al. 1996), sleep deprivation may still be a stressful procedure. It has been shown that injections of corticosterone can increase levels of contextual fear conditioning if administered acutely after training (Pugh et al. 1997a,b). Thus, the effects of acute stress after fear conditioning resulting from sleep deprivation would tend to minimize the differences we observe between sleep-deprived and nonsleep-deprived animals in contextual fear conditioning, and thus would not explain our results. Additionally, it has been shown that even after a $21.5 \mathrm{~h}$ sleep deprivation period, serum corticosterone levels in rats are increased slightly but not significantly (Tobler et al. 1983). Cued fear conditioning also may serve as an additional control for some of the effects of stress on performance during testing for context fear conditioning. Because we see effects of sleep deprivation on contextual, but not cued conditioning, it is unlikely that our results are due to nonspecific impairments in performance that follow sleep deprivation.

Experiments have suggested that discrete periods of time after training for fear conditioning are sensitive to protein synthesis and PKA inhibitors (Bernabeu et al. 1997; Bourtchouladze et al. 1998; Schafe et al. 1999). When animals are administered a protein synthesis inhibitor or a PKA inhibitor immediately or at a time point $4 \mathrm{~h}$ after training for fear conditioning, memory consolidation for contextual fear

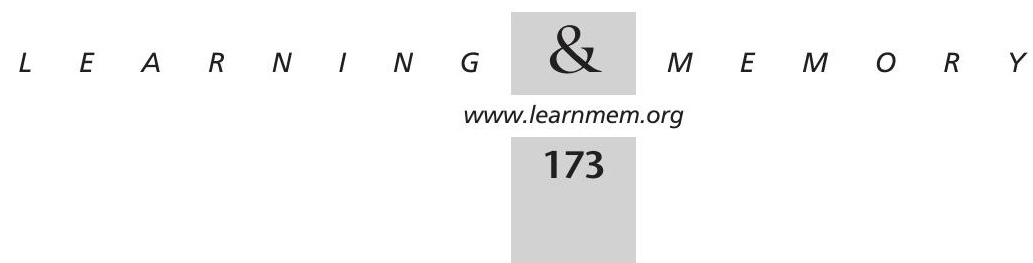


conditioning is disrupted (Bourtchouladze et al. 1998). No disruption is seen with manipulation at other time points after training. This common requirement for PKA and protein synthesis at discrete time points after training has led to the suggestion that the PKA signaling cascade leads to the induction of gene expression and the synthesis of new proteins during these time windows. Because it has been demonstrated that the times immediately and $4 \mathrm{~h}$ after training, but not $6 \mathrm{~h}$ after training, for fear conditioning are selectively sensitive to PKA and protein synthesis disruption, and because the time period from $0-5 \mathrm{~h}$ after fear conditioning but not from 5-10 h after fear conditioning is sensitive to sleep deprivation, our experiments support the idea that sleep deprivation and protein synthesis or PKA disruption may be acting in common ways. Specific effects of sleep deprivation on PKA or protein synthesis could be through disruption of a REM cholinergic flux, which can regulate cAMP/PKA signaling and protein synthesis (for review, see Graves et al. 2001). Both acetylcholine and 5-HT have been shown to be important for consolidation of memory (for review, see Graves et al. 2001). For instance, the administration of scopolamine, a muscarinic acetylcholine antagonist, to rats after fear conditioning impairs memory (Rudy 1996), as does administration of agonists and antagonists of various subtypes of 5-HT receptors (Meneses 1998).

It has been proposed that normally occurring changes in sleep after training for some behavioral tasks could be one way that sleep modulates memory consolidation (Smith 1996; Graves et al. 2001; Stickgold et al. 2001). For instance, in the Morris water maze, there are increases in REM sleep after training in rats (Smith and Rose 1997), and sleep deprivation during some of the times when there is increased REM sleep impairs memory consolidation for that task (Smith and Rose 1996). However, after training for a very stringent protocol in fear conditioning, REM sleep is decreased in mice (Sanford et al. 2001). Future work will need to examine whether there are changes in REM or NREM sleep during memory consolidation for fear conditioning using a training protocol similar to the one shown here to be sensitive to sleep deprivation.

In summary, we have identified a 5 -h time window immediately posttraining during which sleep deprivation selectively impairs memory consolidation for a hippocampus-dependent task. This effect is dependent on the time after training during which a mouse is sleep deprived because sleep deprivation at later times after training had no effect. Our experiments are an initial step to elucidate the molecular underpinnings of the effects of sleep deprivation on memory consolidation by first localizing the neural systems involved and the timing of the effects. The results of these experiments lay the behavioral groundwork for an examination of the molecular processes underlying the role of sleep in memory consolidation.

\section{MATERIALS AND METHODS}

\section{Training Procedure}

Equal numbers of 8-12-week-old male and female C57BL/6J mice were trained as described previously (Abel et al. 1997). All experiments were approved by the Institution of Animal Care and Use Committee of the University of Pennsylvania and were carried out in accordance with all National Institutes of Health guidelines. Mice were maintained on a $12 \mathrm{~h} / 12 \mathrm{~h}$ light/dark schedule with lights on at $7 \mathrm{am}$ (ZT 0) and off at $7 \mathrm{pm}$ (ZT 12). Mice were trained in a rectangular chamber $\left(16^{\prime \prime} \mathrm{L} \times 6^{\prime \prime} \mathrm{W} \times 83 / 8^{\prime \prime} \mathrm{H}\right)$ with two walls made of clear Plexiglas, two walls made of metal (Med Associates), and a shock grid floor that was connected to a Med Associates Shock-Grid Scrambler shocking apparatus. The chamber was located in a windowless, dimly lit room, in a sound-attenuated box $\left(22^{\prime \prime} \mathrm{W} \times 15^{\prime \prime} \mathrm{H} \times 14^{\prime \prime} \mathrm{D}\right)$ with a clear window that allowed the experimenter to observe the mice. The chamber was divided in half by a closed divider and all mice were placed in the left half of the chamber. A fan provided background noise ( $65 \mathrm{~dB})$. Between each mouse the chamber was washed with $70 \%$ ethanol. Mice were handled for 2 min each for each of 3 d before the start of each experiment at the approximate time at which they were trained. On the training day, each mouse was carried to the testing room in a cage with shavings from its home cage and was placed into the chamber for $2 \mathrm{~min}$ before the onset of the CS, which consisted of white noise $(10-25,000 \mathrm{~Hz}, 83 \mathrm{~dB})$. The last $2 \mathrm{sec}$ of the CS were paired with a $1.5-\mathrm{mA}$ footshock. After another $30 \mathrm{sec}$, the mouse was returned to its home cage. All mice were trained at the same circadian time, with training starting at ZT $5(\mathrm{ZT} 0=7 \mathrm{am})$.

\section{Sleep Deprivation}

After training, nonsleep-deprived mice were left undisturbed in their home cages and sleep-deprived mice were kept awake in their home cages by gentle stroking (Ledoux et al. 1996) to arouse them from sleep for $5 \mathrm{~h}$, from either $0 \mathrm{~h}$ to $5 \mathrm{~h}$ after training or from $5 \mathrm{~h}$ to $10 \mathrm{~h}$ after training. All experiments were balanced between sleep-deprived and nonsleep-deprived mice

\section{Testing Procedure}

Mice were tested for 5 min for contextual fear (context) by assessing "freezing" in the original shocked context $24 \mathrm{~h}$ after training Freezing behavior was assessed at intervals of $5 \mathrm{sec}$ and was defined as complete lack of movement, except for respiration (Blanchard and Blanchard 1969; Fanselow 1980). Approximately $1 \mathrm{~h}$ later, mice were tested for $5 \mathrm{~min}$ in an altered context in which baseline freezing in the altered context in the absence of the conditioned stimulus was assessed for $2 \mathrm{~min}$ (pre CS) and freezing in response to the CS was assessed for the remaining $3 \mathrm{~min}$. For the altered chamber, the floor and sides of the original chamber were replaced with smooth, black panels and the chamber was divided in half diagonally. The fan was disconnected and between mice the chamber was washed with a 15\% Lemon Joy/water (Procter\&Gamble) mixture. The order of testing of sleep-deprived and nonsleepdeprived mice for the context test was random. The order of testing for the cued test was the same as for the context test.

To measure generalized freezing in response to the cue alone, an additional group of mice that received no noise-shock pairing during training were tested in the altered chamber with the noise CS $24 \mathrm{~h}$ after training. To control for the strength of conditioning in response to the cue, an additional group of mice were trained using a tone CS $(2800 \mathrm{~Hz}, 85 \mathrm{~dB})$. Because the tone is less salient than the

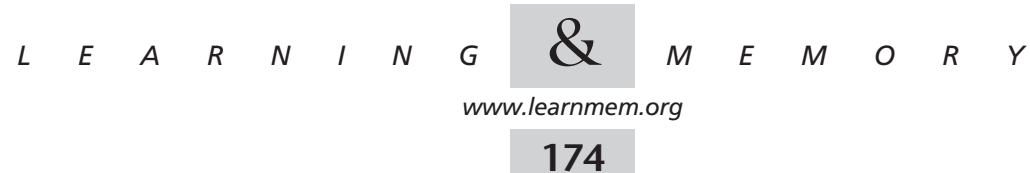


noise, mice display less conditioned fear in response to it. This enabled us to determine if the effects of sleep deprivation on learning and memory were dependent on the strength of cued conditioning. To control for the order of testing on cued and contextual fear conditioning, we tested an additional group of mice with the cued test prior to the contextual test.

\section{Data Analysis}

Levels of freezing were calculated by counting the number of times during each test, at $5 \mathrm{sec}$ intervals, that the mouse was observed to be freezing (Abel et al. 1997). This number was expressed as a percentage of the overall number of observations during each test. Freezing levels were calculated for each test of context, pre CS, and CS. In addition, a "delta context" score was calculated by subtracting the percent freezing in the altered context in the absence of the cue (pre CS) from the percent freezing in the original, shocked context (Paylor et al. 1994; Valentinuzzi et al. 2001). This score reflects freezing that is specific to the shocked context, a measure that is thought to be especially sensitive to hippocampal lesions (Frankland et al. 1998). A "delta cue" score was calculated by subtracting the percent freezing in the absence of the cue in the altered context (pre CS) from the percent freezing in response to the cue (CS). This score reflects freezing that is specific to the cue. In all experiments, data was analyzed using a two-way ANOVA (SigmaStat v. 2.0). For each experiment one ANOVA was performed with main effects of condition of testing (context, pre CS, CS) and sleep (sleep deprived or nonsleep deprived), as well as interactions between condition of testing and sleep. For each experiment, one ANOVA was performed with main effects of condition of testing (delta context or delta cue) and sleep (sleep deprived or nonsleep deprived), as well as interactions between condition of testing and sleep. For post-hoc analyses, a StudentNeuman-Keuls test was used. All $P$ values expressed in this paper reflect those of post-hoc analyses. No sex differences were seen in fear conditioning or in the effects of sleep deprivation, so results from male and female mice were pooled. All results are reported as mean + /- SEM. Numbers of subjects for each experiment are reported in the appropriate figure legends.

\section{ACKNOWLEDGMENTS}

We thank Kevin Hellman, K. Matthew Lattal, and Thomas J. Gould for their advice and Michele Kelly for her assistance with the statistical analysis. This work was supported by grants from the NIH to L.A.G. (5T32AG-00256), A.I.P. (HL-60287; 5T32AG-00256), and T.A. (AG-18199, MH-60244), as well as grants from the Whitehall Foundation, the University of Pennsylvania Research Foundation, and a Young Investigator Award from the Mental Retardation and Developmental Disabilities Research Center at Children's Hospital of Philadelphia (HD-26979) to T.A. T.A. is a John Merck Scholar and a Packard Foundation Fellow.

The publication costs of this article were defrayed in part by payment of page charges. This article must therefore be hereby marked "advertisement" in accordance with 18 USC section 1734 solely to indicate this fact.

\section{REFERENCES}

Abel, T. and Lattal, K.M. 2001. Molecular mechanisms of memory acquisition, consolidation and retrieval. Curr. Opin. Neurobiol. 11: $180-187$

Abel, T., Nguyen, P.V., Barad, M., Deuel, T.A.S., Kandel, E.R., and Bourtchouladze, R. 1997. Genetic demonstration of a role for PKA in the late phase of LTP and in hippocampus-based long-term memory. Cell 88: 615-626.

Bernabeu, R., Bevilaqua, L., Ardenghi, P., Bromberg, E., Schmitz, P., Bianchin, M., Izquierdo, I., and Medina, J.H. 1997. Involvement of hippocampal cAMP/cAMP-dependent protein kinase signaling pathways in a late memory consolidation phase of aversively motivated learning in rats. Proc. Natl. Acad. Sci. 94: 7041-7046.

Blanchard, R.J. and Blanchard, D.C. 1969. Crouching as an index of fear. $J$. Comp. Physiol. Psychol. 67: 370-375.

Bourtchouladze, R., Abel, T., Berman, N., Gordon, R., Lapidus, K., and Kandel, E.R. 1998. Different training procedures for contextual memory in mice can recruit either one or two critical periods for memory consolidation that require protein synthesis and PKA. Learn. Mem. 5: 365-374.

Devan, B.D., Goad, E.H., Petri, H.L., Antoniadis, E.A., Hong, N.S., Ko, C.H., Leblanc, L., Lebovic, S.S., Lo, Q., Ralph, M.R., et al. 2001. Circadian phase-shifted rats show normal acquisition but impaired long-term retention of place information in the water task. Neurobio. Learn. Mem. 75: 51-62.

Fanselow, M.S. 1980. Conditional and unconditional components of post-shock freezing. Pavlovian J. Biol. Sci. 95: 177-182.

Frankland, P.W., Cestari, V., Filipkowski, R.K., McDonald, R.J., and Silva, A.J. 1998. The dorsal hippocampus is essential for context discrimination but not for contextual conditioning. Behav. Neurosci. 112: $863-874$

Graves, L., Pack, A., and Abel, T. 1999. The role of sleep in hippocampus-dependent long-term memory. Soc. Neurosci. Abstr. 25: 87.

Graves, L., Pack, A., and Abel, T. 2001. Sleep and memory: A molecular perspective. Trends Neurosci. 24: 237-243.

Holland, P.C. and Bouton, M.E. 1999. Hippocampus and context in classical conditioning. Curr. Opin. Neurobiol. 9: 195-202.

Izquierdo, I. and Medina, J.H. 1997. Memory formation: The sequence of biochemical events in the hippocampus and its connection to activity in other brain structures. Neurobiol. Learn. Mem. 68: 285-316.

LeDoux, J.E. 2000. Emotion circuits in the brain. Annu. Rev. Neurosci. 23: $155-184$.

Ledoux, L., Sastre, J.P., Buda, C., Luppi, P.H., and Jouvet, M. 1996. Alterations in c-fos expression after different experimental procedures of sleep deprivation in the cat. Brain Res. 735: 108-118.

Lipp, H.P. and Wolfer, D.P. 1998. Genetically modified mice and cognition. Curr. Opin. Neurobiol. 8: 272-280.

Maren, S. 2001. Neurobiology of Pavlovian fear conditioning. Ann. Rev. Neurosci. 24: 897-931.

Meneses, A. 1998. Physiological, pathophysiological and therapeutic roles of 5-HT systems in learning and memory. Rev. Neurosci. 9: 275-289.

Morris, R.G.M., Garrud, P., Rawlins, J.N.P., and O'Keefe, J. 1982. Place navigation impaired in rats with hippocampal lesions. Nature 297: 681-683.

Paylor, R., Tracy, R., Wehner, J., and Rudy, J.W. 1994. DBA/2 and C57BL/6 mice differ in contextual fear but not auditory fear conditioning. Behav. Neurosci. 108: 810-817.

Pugh, C.R., Fleshner, M., and Rudy, J.W. 1997a. Type II glucocorticoid receptor antagonists impair contextual but not auditory-cue fear conditioning in juvenile rats. Neurobiol. Learn. Mem. 67: 75-79.

Pugh, C.R., Tremblay, D., Fleshner, M., and Rudy, J.W. 1997b. A selective role for corticosterone in contextual-fear conditioning. Behav. Neurosci. 111: 503-511.

Rechtschaffen, A. 1998. Current perspectives on the function of sleep Perspect. Biol. Med. 41: 359-390.

Rudy, J.W. 1996. Scopolamine administered before and after training impairs both contextual and auditory-cue fear conditioning. Neurobiol. Learn. Mem. 65: 73-81.

Rudy, J.W. and Pugh, C.R. 1998. Time of conditioning selectively influences contextual fear conditioning: Further support for a multiple-memory systems view of fear conditioning. J. Exp. Psychol. Anim. Behav. Process 24: 316-324.

Sanford, L.D., Silvestri, A.J., Ross, R.J., and Morrison, A.R. 2001. Influence

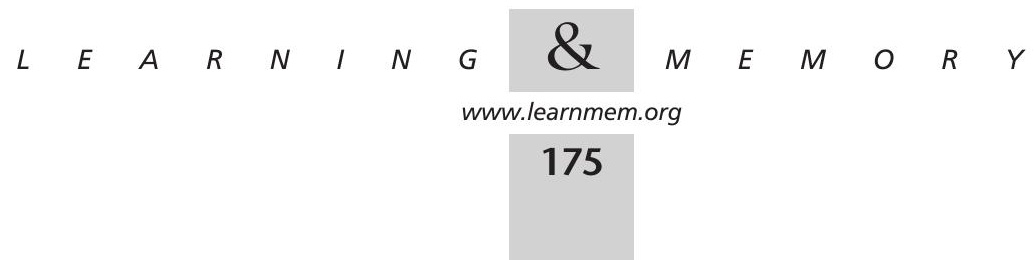


of fear conditioning on elicited ponto-geniculo-occipital waves and rapid eye movement sleep. Arch. Ital. Biol. 139: 169-183.

Schafe, G.E., Nadel, N.V., Sullivan, G.M., Harris, A., and LeDoux, J.E. 1999 Memory consolidation for contextual and auditory fear conditioning is dependent on protein synthesis, PKA, and MAP kinase. Learn. Mem. 6: $97-110$.

Schenk, F. and Morris, R.G.M. 1985. Dissociation between components of a spatial memory in rats after recovery from the effects of retrohippocampal lesion. Exp. Brain Res. 58: 11-28.

Smith, C. 1996. Sleep states, memory processes and synaptic plasticity. Behav. Brain Res. 78: 49-56.

Smith, C. and Rose, G.M. 1996. Evidence for a paradoxical sleep window for place learning in the Morris water maze. Physiol. Behav. 59: 93-97.

Smith, C. and Rose, G.M. 1997. Posttraining paradoxical sleep in rats is increased after spatial learning in the Morris water maze. Behav. Neurosci. 111: 1197-1204.

Stickgold, R., Scott, L., Rittenhouse, C., and Hobson, J.A. 1999 Sleep-induced changes in associative memory. J. Cogn. Neurosci. 11: $182-193$.
Stickgold, R., Whidbee, D., Schirmer, B., Patel, V., and Hobson, J.A. 2000. Visual discrimination task improvement: A multi-step process occurring during sleep. J. Cogn. Neurosci. 12: 246-254.

Stickgold, R., Hobson, J.A., Fosse, R., and Fosse, M. 2001. Sleep, learning, and dreams: Off-line memory reprocessing. Science 294: 1052-1057.

Tobler, I., Murison, R., Ursin, R., Ursin, H., and Borbely, A.A. 1983. The effect of sleep deprivation and recovery sleep on plasma corticosterone in the rat. Neurosci. Lett. 35: 297-300.

Valentinuzzi, V.S., Kolker, D.E., Vitaterna, M.H., Ferrari, E.A., Takahashi, J.S., and Turek, F.W. 2001. Effect of circadian phase on context and cued fear conditioning in C57BL/6J mice. Animal Learn. Behav 29: 133-142.

Veasey, S.C., Valladares, O., Fenik, P., Kapfhamer, D., Sanford, L., Benington, J., and Bucan, M. 2000. An automated system for recording and analysis of sleep in mice. Sleep 23: 1025-1040.

Received March 28, 2002; accepted in revised form April 1, 2003.

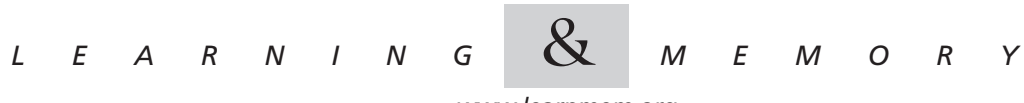

www.learnmem.org 


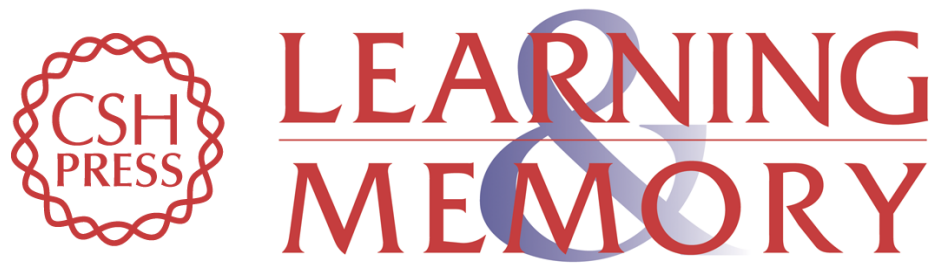

\section{Sleep Deprivation Selectively Impairs Memory Consolidation for Contextual Fear Conditioning}

Laurel A. Graves, Elizabeth A. Heller, Allan I. Pack, et al.

Learn. Mem. 2003, 10:

Access the most recent version at doi:10.1101/lm.48803

References This article cites 33 articles, 4 of which can be accessed free at:

http://learnmem.cshlp.org/content/10/3/168.full.html\#ref-list-1

License

Email Alerting Receive free email alerts when new articles cite this article - sign up in the box at the Service top right corner of the article or click here. 